\title{
How to meet the demand for good quality renal dialysis as part of universal health coverage in resource-limited settings?
}

\author{
Yot Teerawattananon, Alia Luz*, Songyot Pilasant, Suteenoot Tangsathitkulchai, Sarocha Chootipongchaivat,
} Nattha Tritasavit, Inthira Yamabhai and Sripen Tantivess

\begin{abstract}
Background: It is very challenging for resource-limited settings to introduce universal health coverage (UHC), particularly regarding the inclusion of high-cost renal dialysis as part of the UHC benefit package. This paper addresses three issues: (1) whether a setting commits to include renal dialysis in its UHC benefit package and if so, why and how; (2) how to ensure quality of renal dialysis services; and (3) how to improve the quality of life of patients using psychosocial and community interventions.

Discussion: This article reviews experiences of renal dialysis programs in seven settings based on presentations and discussions during the International Forum on Peritoneal Dialysis as a Priority Health Policy in Asia. A literature review was conducted to verify and validate the data as well as to fill information gaps presented in the forum.

Five out of the seven settings implemented renal dialysis as part of their benefits package, while the other two have pilots or programs in their nascent stage. Renal replacement therapy has become part of the universal access package because these governments recognize the rising number of chronic kidney disease (CKD) cases, the catastrophically high costs of treatment, and that this is the only life-saving treatment available to patients. The recommendations are as follows: Governments should have a holistic approach to CKD interventions, including primary prevention as well as psychosocial interventions. Governments should consider subsidizing CKD treatment costs depending on their resources. Multi-stakeholder cooperation should be facilitated to enact these policies and conduct research and development for all aspects of interventions. International collaboration should be initiated to share experiences, good practices, and joint activities (e.g. capacity building and multinational procurement of medical supplies).
\end{abstract}

Conclusion: This study provides practical recommendations to country governments as well as the international community on how to meet the demand for good quality renal dialysis as part of UHC in resource-limited settings.

Keywords: Chronic kidney disease, End-stage renal disease, Low- and middle-income countries, Peritoneal dialysis, Renal replacement therapy, Universal health coverage

\section{Background}

During the last decade, many low- and middle-income countries (LMICs) declared major reforms in their health systems to achieve universal health coverage (UHC). Although UHC has been differently interpreted, defined and translated into action [1], the ultimate goal

\footnotetext{
*Correspondence: alialuz90@gmail.com

Health Intervention and Technology Assessment Program (HITAP),

Department of Health, Ministry of Public Health, Tiwanon road, Nonthaburi 11000, Thailand
}

(C) 2016 Teerawattananon et al. Open Access This article is distributed under the terms of the Creative Commons Attribution 4.0 International License (http://creativecommons.org/licenses/by/4.0/), which permits unrestricted use, distribution, and reproduction in any medium, provided you give appropriate credit to the original author(s) and the source, provide a link to the Creative Commons license, and indicate if changes were made. The Creative Commons Public Domain Dedication waiver (http://creativecommons.org/publicdomain/zero/1.0/) applies to the data made available in this article, unless otherwise stated.

of such a policy as proposed by WHO is to promote population health by ensuring universal access to essential healthcare of high quality, protecting people from health impoverishment and improving equity in health across socioeconomic groups [2]. In so doing, country governments need to take into consideration three key dimensions, namely the population to be covered as beneficiaries, the services to be included in the benefit package, and the proportion of public subsidization for healthcare provision [3]. Following the World Health 
Assembly resolution on sustainable health financing for $\mathrm{UHC}$, the policy options to be adopted should be pertinent to the economic, sociocultural and political context of each country [4].

Every country which moves towards UHC has to raise additional funds, either from domestic sources or from international development support [3]. It is evident that, in many LMICs, additional public resources have been mobilized in order to guarantee access to the necessary services for all people in need. For instance, in Thailand, where a UHC scheme was established in 2002, government spending on health has continued to grow, and a significant increase of $75 \%$ was observed between 2005 and 2010 [5]. However, the demand for a higher level of public health budget cannot be met in all countries, although innovative financing mechanisms have already been introduced. In particular, most resource-poor settings have been facing a double burden of infectious diseases and non-communicable diseases [6]. Some argue that increasing access to healthcare can yield substantial economic benefits in the macro and micro level, including protecting households from illness-related catastrophe [2]. However, since it is usually difficult to link economic growth with health investment, and since it takes a long time to see economic contribution of health initiatives, allocating a large amount of the already limited resources to UHC or even particularly expensive health interventions is politically challenging [7].

Renal replacement therapy (RRT), including renal dialysis and transplantation, for end-stage renal disease (ESRD) is a high-cost, albeit life-saving service. On a global level, it is estimated that 1 in every 20 people have chronic kidney disease (CKD). ESRD - the last and most critical stage of CKD - is a growing problem in most countries. Its incidence is increasing globally at an annual growth rate of $8 \%$ [8]. The 2014 United States Renal Data System report shows that the incidence of ESRD increased by $10 \%$ (per million population) from 2006 to 2012 in Korea, Malaysia, Mexico, Thailand, and the USA [9]. People over 65 years of age are more vulnerable to CKD than those in other age groups, and also have a higher probability of death [8]. The vascular and systemic complications in this subpopulation does not make them optimal candidates for renal transplantation, and they are less likely to receive a kidney from a living related donor. The costs for RRT are generally too high for most patients in developing countries to afford [10]. Furthermore, kidney donor and transplantation services are not widely available in resource-limited settings [11]. Liyanage et al. [12] estimated that, in 2010, around 2.3 million people died from lack of access to RRT, and worldwide use of RRT will double from 2.6 million to 5.4 million people by 2030. Providing treatment for ESRD patients is becoming more of a concern, especially since most treatment options are costly and would need to be balanced with provision of other health services.

Despite the notable budget implication of RRT, some countries have made strides towards alleviating the burdens for ESRD by subsidizing renal dialysis for their people, with or without co-payment from households. Besides the financial obstacle, inadequate infrastructure and trained personnel are major supply-side barriers to UHC of renal dialysis in resource-poor settings [10]. At the same time, access and adherence to long-term health services are hindered by factors of the demand side. For renal dialysis, these include effective coverage, quality and health outcomes of two major modalities, peritoneal dialysis (PD) and haemodialysis (HD), which are associated with living circumstances, employment and education of ESRD patients; support from family members and community networks; and contextual elements such as distance between patients' residence and health facilities and convenience in transportation [13, 14]. This means that providing universal access to renal dialysis requires not only public finance, but also suitable, integrated measures to address all the impediments.

Based on presentations and discussion during the International Forum on Peritoneal Dialysis as a Priority Health Policy in Asia, held in November 2014 in Bangkok, this article reviews experiences of renal dialysis programs in seven settings, namely Hong Kong, Indonesia, Malaysia, the Philippines, Taiwan, Thailand, and the United Kingdom. It emphasizes policy response to the rising CKD burden, clinical innovations to ensure quality of care, and psychosocial support provided by paramedics, community, non-governmental organizations and patient networks in each country context. The information gathered from personal communication to the experts was part of the preparation of the workshop and was also taken into account. Additionally, a literature review was conducted to verify and validate as well as fill information gaps presented in the forum. This paper will provide guidance to LMICs committed to UHC on effective ways to respond to the challenging issue of providing treatment to ESRD patients. Table 1 illustrates country/setting profiles in relation to their UHC policy and burden of CKD.

\section{Review}

Do countries committed to UHC implement renal dialysis? Why and how?

Out of the seven study settings, five settings, including the United Kingdom in the 1960s, Hong Kong in 1985 (PD-first policy) [15], Taiwan in 1995 [16], Malaysia in 2001 [17] and Thailand in 2008 [18], have implemented universal access to renal dialysis. The Philippines issued a national policy in 2014 for renal dialysis and implementation is in the early phase. For Indonesia, they have 
Table 1 Country/setting profiles for health systems and renal disease profiles

\begin{tabular}{|c|c|c|c|c|c|c|}
\hline Country/Setting & $\begin{array}{l}\text { Pledged year of } \\
\text { achieving Universal } \\
\text { Health Coverage }\end{array}$ & $\begin{array}{l}\text { Population } \\
\text { (million) } \\
\text { (2013) [56] }\end{array}$ & $\begin{array}{l}\text { Gross Domestic } \\
\text { Product (GDP) per } \\
\text { capita (USD) (2013) [57] }\end{array}$ & $\begin{array}{l}\text { Total health } \\
\text { expenditure as \% } \\
\text { GDP (2012) [58] }\end{array}$ & $\begin{array}{l}\text { Prevalence of } \\
\text { diabetes, per million } \\
\text { population (2014) [59] }\end{array}$ & $\begin{array}{l}\text { Prevalence of end-stage } \\
\text { renal disease, per million } \\
\text { population }(2012)[9,34]\end{array}$ \\
\hline $\begin{array}{l}\text { Hong Kong Special } \\
\text { Administrative Region }\end{array}$ & $1993[60,61]$ & 7.2 & $38,123.5$ & $5.1[62]$ & 99,200 & 1,192 \\
\hline Indonesia & $2019[63,64]$ & 249.9 & $3,475.3$ & 3.0 & 58,100 & 265 \\
\hline Malaysia & 1980s [65] & 29.7 & $10,538.1$ & 3.9 & 166,100 & 1,056 \\
\hline The Philippines & $2016[66,67]$ & 98.4 & $2,765.1$ & 4.6 & 58,900 & 103 \\
\hline Taiwan (Chinese Taipei) & $1995[68]$ & 23.4 [69] & $20,924.9[69]$ & $6.6[70]$ & 99,200 & 2,902 \\
\hline Thailand & 2002 [71] & 67.0 & $5,779.0$ & 3.9 & 84,500 & 906 \\
\hline The United Kingdom & 1948 [72] & 64.1 & $41,787.5$ & 9.4 & 53,800 & 876 \\
\hline
\end{tabular}

pilot programs and these are under consideration for inclusion in the benefit package. The governments of these five settings (though not all) implemented this program, which is the only life-saving treatment feasible for many reasons. In the United Kingdom, both renal transplantation and dialysis have been provided in the National Health Service since the 1960s. By the end of 2013, $52 \%, 41.6 \%$ and $6.4 \%$ of the RRT patients in the United Kingdom received a transplantation, HD and PD, respectively [19]. In Hong Kong and Taiwan, despite the capacity and financial resources to provide renal transplantation, the majority of the population is Chinese and hold a belief against organ donation [20-22]. Thailand and the Philippines do not have enough capacity and financial resources to offer renal transplantation. For instance, the limited supply of donated kidneys [23], lack of infrastructure [10], and shortage of specialized health professionals in the public sector [24] are major barriers to transplantation. Although many studies have demonstrated that renal transplantation is more cost-effective compared to dialysis [25-27], these studies have mostly focused on high-income countries and therefore did not account for costs such as infrastructure development and human resources. Further, research $[28,29]$ showed that the estimated costs of renal transplantations tend to be higher in the first few years compared to dialysis, which could impact the healthcare budget of developing countries more severely compared to that of developed countries.

In this case, renal dialysis emerges as the most viable option. Apart from being a life-saving treatment, paying for dialysis is well-regarded as a common cause of catastrophic household health expenditure. It was documented that the annual cost of dialysis was 7-48 times higher than the average income of populations in many OECD countries [30]. This is one of the main reasons that many governments decided to include dialysis in their benefit packages.

Among the five countries that introduced access to renal dialysis, each has a different policy regarding dialysis modalities and may be divided into two groups. The first group, Malaysia, Taiwan, and the United Kingdom, offers choices for patients and providers to opt for HD or PD. Patients have no incentive or disincentive to choose the treatment they receive. However, HD is the more frequently chosen dialysis modality, probably due to provider financial incentives as it requires more frequent HD unit visits, resulting in higher professional and HD unit fee earnings. In these three settings, HD accounts for $88 \%$ in Malaysia (versus 12\% for PD), 91\% in Taiwan (versus 9\% for PD), and $43 \%$ in the United Kingdom (versus $7 \%$ for PD) [31-35]. On the contrary, the second group, Hong Kong and Thailand, has instituted a policy on PD as the first-line treatment through the creation of incentives for provider and patient PD use. This includes full reimbursement of PD and only reimburses HD for patients with contraindications for PD. In Thailand, the UHC scheme offers capital investment for PD providers, free training for health professionals and infrastructure development. Moreover, the Thai UHC scheme also allows health professionals to receive a professional fee for providing PD services. As a result, as of 2012, more than 70\% of ESRD patients in Hong Kong and $42 \%$ of new ESRD patients under the UHC in Thailand now use PD as their treatment [34, 36].

Experiences from Hong Kong [37] and Thailand [38] demonstrate that PD has relatively lower cost for providers (including capital investment), less healthcare provider staff needed, and much lower travel time and cost for patients, leading to increased patient autonomy and satisfaction. This lower travel time and cost for patients reflects the results of a study in South India indicating that direct medical care costs for haemodialysis accounts for only $55 \%$ of the total cost, whereas direct nonmedical costs, e.g. travel costs, account for around 20\% and indirect costs, e.g. opportunity cost loss from work, account for $25 \%$ of the total cost [39]. The latter two components make haemodialysis unaffordable by the majority of the population even if dialysis is offered for free. In Thailand, many rural hospitals have successfully 
implemented PD services for patients who are living in remote areas (e.g. mountain villages) as patients have no need to travel to health facilities often and can administer the treatment themselves at home [40]. Nevertheless, patients experience higher complications such as peritoneal infections due to poor education and those in low socio-economic groups (though they may also have difficulties accessing HD). Caregiver and patient burn-out is also a challenge. HD, on the other hand, has advantages as described by speakers from Malaysia, the Philippines and Taiwan. For example, less patient responsibility and higher provider comfort with the HD process. In the literature, authors found that HD offers better patient socialization as they gather together in the HD units for long periods of time [41].

In Indonesia and the Philippines, where the incidence of ESRD and haemodialysis facilities have gradually been increased simultaneously, RRT is categorized as a highcost treatment for ESRD. Most patients cannot afford access to the treatment. Therefore, government health insurance recently included RRT in their benefit package, though in practice, the effective coverage is limited. For example, the cost of dialysis is partially supported with certain co-payments that remain unaffordable for the poor $[42,43]$. The majority of patients in Asia remain unable to access RRT. It was estimated that the gap between the actual number of patients undergoing RRT and the estimated number of patients with ESRD is very high. For example, in Indonesia, there are around 100,000 people who need RRT but do not have access to the treatment [44].

PD and HD each have their advantages and disadvantages (Table 2) [41, 45, 46]. While PD provides several advantages in terms of clinical outcomes, government treatment implementation, and patient uptake and access, the selection of PD or HD will usually be based on patient motivation, desire, geographic distance from an HD unit, physician and/or nurse bias, patient education and reimbursement policies [47]. Unfortunately, many patients are not educated on PD before beginning dialysis [48]. However, PD can improve patient survival in the first few years, retain residual kidney function, lower infection risk, and increase patient satisfaction while reducing financial stress to governments by addressing the burden of managing the growing number of ESRD patients [49].

The governments in Thailand and Hong Kong introduced the PD first policy in order to ensure that PD is promoted over HD based on the reasons stated above. This policy can be seen as a limitation of freedom of patient choice. Nevertheless, it can be argued that government priority is to ensure overall societal benefit, and in these circumstances, the individual benefit may not always be in line with society's interests and choice may not be available to all [50]. For example, if most patients are given the choice between PD and HD, the budget may be insufficient to cover to the last patient or only patients in urban areas are able to choose between PD and HD, while patients in rural areas may receive only PD.

In conclusion, most settings committed to UHC implemented universal access to renal dialysis because renal dialysis is an essential service; it is life-saving without a better alternative except transplantation, for which efforts should continuously be made in order to make donation and transplantation more widely available. Despite incurring a high cost and not representing good value for money, the governments of these settings consider that the inclusion of renal dialysis is aligned with the objectives of UHC in terms of financial protection. There may be several factors, such as geography and political economy, which affect governments' decisions to promote either dialysis modality. Experiences from these five settings show that governments contending with the following factors should opt for PD as the first-line treatment: limited UHC budget allocation for dialysis program, less human resources for health, and geographical difficulties in healthcare facility access.

\section{How to ensure quality of care}

Clinical care for ESRD patients should be considered as part of the integrated care for CKD patients. A holistic approach to observe the progression of the disease since the early stage should be taken into account. Healthcare systems should be able to identify populations at risk of CKD and CKD patients in the early stage of the disease in order to provide appropriate care and support and

Table 2 Comparison of advantages and disadvantages of haemodialysis and peritoneal dialysis

\begin{tabular}{lll}
\hline & Haemodialysis (in centre, hospital) & Peritoneal dialysis \\
\hline Advantages & $\cdot$ Patient does not need to be taught to carry out treatment & $\cdot$ Better survival rate within the first 1-2 years \\
& $\cdot$ Social support system & $\cdot$ Increased patient autonomy \\
& $\cdot$ Applicable to a majority of patients & $\cdot$ Lower cost \\
Disadvantages & $\cdot$ Increased time and cost associated with transportation to the hospital & $\cdot$ Patients must be disciplined about maintaining hygiene \\
& $\cdot$ Increased risk of infection or complications & $\cdot$ Technique failure may lead to infection or complications \\
& & $\cdot$ Potential burnout of patients or caregivers \\
\hline
\end{tabular}


delay disease progression [30]. Healthcare systems should not only focus on investing in clinical care for CKD patients, but there should also be more primary prevention efforts such as promoting a healthy lifestyle (exercise and appropriate diet, e.g. salt and sugar restriction). Experts from all settings had consensus that primary healthcare is an instrumental mechanism as they can reach the majority of the population who are at risk. A study in Bhutan informed that introducing universal access to the Package of Essential Non-communicable disease interventions, including population-based screening and early treatment for diabetes and hypertension, offers very good value for money [51].

All settings that participated in the forum established a RRT registry, which is a database with information on patients undertaking dialysis and/or kidney transplantation. This database can track ESRD patients' accessibility to RRT by comparing the number of new patients registered to the database to the estimated number of patients based on epidemiological studies; assess quality of RRT services through analysis of survival rates, rate of developing complication(s) or switching between modalities; and patient discontinuation of dialysis treatment. Although the available databases in these settings are at different levels of quality, they should also have information on the socioeconomic status and geographical location of patients in addition to the medical information [52].

In addition, a financial mechanism should be developed to ensure that governments are investing in good quality services and care for renal dialysis. In the United Kingdom, the government developed renalspecific quality indicators, such as blood pressure regulation by angiotensin converting enzyme inhibitors or angiotensin II receptor blocker drugs, and disease progression monitoring by measuring urine albumin and creatinine ratio test [53]. The providers will have incentives to provide this service because they are deemed to be an important part of clinical care. There is strong evidence linking angiotensin converting enzyme inhibitors and angiotensin II receptor blocker drugs with the delay of renal disease progression [54].

In Thailand, palliative care is delivered to ESRD patients who decide to receive palliative care instead of the standard treatment of PD and HD, especially those that are terminally ill or very old. In addition, some patients may have PD and HD for a certain period of time and at some point decide to voluntarily withdraw from treatment. It is important to note that palliative care does not mean lack of care, but it is the provision of medical, physical, and mental support to the patient and their caregiver to ensure that patients at the terminal stage receive humane care [55].

\section{Improving quality of life of ESRD patients: everybody's business}

CKD has been shown to negatively affect more than just a patient's physical state of health. It is important to recognize the negative impact that a lifelong or longterm illness has on a person's quality of life. Depression in patients with renal failure can be accompanied by anxiety in associated partners, two of the most common psychological complications related to the disease. To address CKD patients' mental health, psychosocial interventions have been put in place by the government in health facilities, healthcare networks, and support centres to improve quality of life. In Thailand, the National Health Security Office has coordinated the creation of networks and volunteer communities for patients with chronic illness since 2003 to provide a space for active volunteers to care for patients. Patient support networks are available for a range of chronic diseases, including renal disease, and these networks work together and collaborate with healthcare professionals to operate a Friendship Support Center in order to provide humanized healthcare [40].

However, the responsibility of ensuring good quality of life for ESRD patients does not lie only with the government - it is also a responsibility of NGOs, the private sector, and communities. Not long after RRT was included in the Thai UHC, Thailand Kidney Friend Clubs were established to extend the Friendship Support networks for CKD patients. The Clubs' activities include providing information about kidney disease and prevention, visiting homes of PD and HD patients, protecting patient rights, and collaborating with the National Health Security Office and Social Security Office in developing the benefits package. In the Philippines, dialysis solution companies also endeavour to improve patient outcomes and help them cope with illness. For example, these companies also raise awareness on the advantages of $\mathrm{PD}$ as a treatment, such as the independence gained from having home-based treatment, which offers a flexible schedule, and maintaining the ability to work and travel. They also work to promote patients' optimism by organizing activities with partners across Asia such as photo contests, sports competitions, walks, and traveling with a PD train (in which the travellers dialyzed while traveling).

Non-governmental efforts to improve patients' quality of life are not limited to support groups but also include financial support that helps alleviate the stress of high cost RRT. In the Philippines, the Kidney Foundation of the Philippines, a non-profit organization, runs the Kidney Care Assistance Program, which provides financial aid to patients on dialysis and transplant operation. Fundraising efforts for patients include an annual 
golf tournament for kidney care, public forums and information campaigns, correspondence to donors and sponsors, media outlets, and kidney care walk-runs.

\section{Conclusions}

This paper addresses the challenges of tackling the increased burden of CKD as part of the UHC policy. Every government's health ministry or related department(s) should have concrete efforts to minimize increasing incidence and clinical progression of CKD. This can be done not just for CKD, but also overlapping with efforts to deal with other diseases and health risks such as hypertension, diabetes, cardiovascular disease, obesity and unhealthy lifestyles. Since treatment of chronic kidney disease can have catastrophically high costs for patients and their families, the governments should consider programs that can subsidize CKD patients' costs to a certain extent, depending on available resources and meeting other competing priorities. As the country's situation changes, governments may revise their policies as appropriate.

Financing, however, is not enough since CKD treatment programs depend on other factors for their success, including human resource development (including more policy-oriented medical education), adequate supply and quality assurance. More research and development for both the clinical and community/psychosocial aspects are needed in order to ensure that the treatment program meets patient needs. This includes creating a patient treatment database. Finally, the government should not be isolated in these efforts; involvement of multiple stakeholders, such as medical associations, industries, civil societies, community groups and networks, and family members, is encouraged.

At the international level, it is important to organize regional forums that bring together not only academics and medical professionals but also decision makers, non-governmental organizations, paramedics and patient group representatives, for sharing experiences, good practices and problem-solving for policy implementation. It is also possible that each country's national database should follow a common regional platform to share information and conduct monitoring and evaluation across countries. These efforts pave the way for future collaborations between countries, such as regional procurement of dialysis solution for a more affordable and reliable supply as well as joint capacity building activities such as regional PD care training for practitioners, physicians, nurses and healthcare workers.

This study has some limitations. The review is selective and not performed in a systematic manner; however, it is based on priority issues discussed during the international forum. In addition, although the authors tried to address the most important issues on renal dialysis under the UHC program, financial models for funding dialysis were not addressed in depth because since these depend on several factors. Funding dialysis should be in line with the financial model for UHC. Some countries, for example the Philippines, have developed innovative financial models using sin tax to fund dialysis and other high-cost medical care, whereas Thailand pays for UHC and dialysis from general tax.

\section{Recommendations}

1. Every government's health ministry or related department(s) should implement concrete efforts to ensure a holistic approach for CKD including primary prevention, especially to promote a healthy lifestyle, screening and prompt treatment of diabetes and hypertension. In addition, psychosocial interventions should also be included in the holistic approach for CKD patients in order to improve their quality of life.

2. Since treatment of CKD can have catastrophically high costs for patients and their families, the governments should consider programs that subsidize CKD patients' costs to a certain extent, depending on available resources and meeting other competing priorities. Financing, however, is not enough because CKD treatment programs need other factors for success such as human resource development (including more policy-oriented medical education), adequate supply and quality assurance. PD First Policy can be considered the policy choice for resource-finite countries committed to UHC.

3. The government should not be isolated in these efforts; involvement of multiple stakeholders, such as medical associations, industries, civil societies, community groups and networks, and family members, is encouraged.

4. Governments and other stakeholders should support research and development for both clinical and community/psychosocial aspects in order to ensure that the treatment program meets patient needs. This includes creating a patient treatment database (e.g. national registry) and community research.

5. Finally, international collaboration should be initiated for sharing experiences, information and good practices, joint capacity building activities, and even multinational procurement of dialysis-related commodities.

\section{Abbreviations}

CKD: Chronic kidney disease; ESRD: End-stage renal disease;

HD: Haemodialysis; LMICs: Low- and middle-income countries; PD: Peritoneal dialysis; RRT: Renal replacement therapy; UHC: Universal health coverage.

Competing interests

The authors declare that they have no competing interests. 


\section{Authors' contributions}

All authors contributed equally in the literature review, writing, analysis and other parts of the manuscript writing process. YT and ST provided guidance on the technical content and structure of the manuscript, in addition to the literature review and writing work they contributed. AL is responsible for corresponding with the journal and reviewers. All authors read and approved the final manuscript.

\section{Authors' information}

The authors are employed by the Health Intervention and Technology Assessment Program, an autonomous research organization affiliated with the Ministry of Health, Thailand.

\section{Acknowledgements}

The authors would like to acknowledge the speakers during the Internationa Forum on Peritoneal Dialysis as a Priority Health Policy in Asia who provided some of the valuable information used or analyzed in this manuscript: Professor Philip KT Li, Dr Donal O'Donaghue, Dr Viroj Tangcharoensathien, Dr Piyathida Cheungsaman, Dr Prateep Dhanakijcharoen, Dr Madeleine Valera, Dr Rully MA Roesli, Dr Siribha Changsrikulchai, Dr Mai Szu-Wu, Dr Lily Mushahar, Dr Arlene Lamban, Ms Orajit Bamrungsakulsawas, Dr Remedios de Belen-Uriarte, and Dr Donna G. de Leon. In addition, the report also gathered information from the participants of the forum and the forum co-hosts to the National Health Security Office (NHSO), namely the Ministry of Health, the Kidney Foundation of Thailand, the Nephrology Society of Thailand, Mahidol University, Health Intervention and Technology Assessment Program (HITAP), the Rockefeller Foundation, and NICE International.

The NHSO of Thailand funded the 'International Forum on Peritoneal Dialysis as a Priority Health Policy in Asia'; the authors did not have any financial support for the writing of this manuscript. However, the HITAP is funded by the Thailand Research Fund under the senior research scholar on Health Technology Assessment (RTA5580010), the National Health Security Office, the Health System Research Institute and the Bureau of Health Policy and Strategy, Ministry of Public Health. HITAP's international unit was established with support from the Thai Health-Global Link Initiative Project, the international Decision Support Initiative (funded by the Bill \& Melinda Gates Foundation and the Department for International Development, UK), and the Rockefeller Foundation to provide technical assistance on health intervention and technology assessment for governments of low- and middle-income countries.

The findings, interpretations and conclusions expressed in this article do not necessarily reflect the views of the aforementioned funding agencies.

\section{Received: 9 September 2015 Accepted: 3 March 2016 Published online: 18 March 2016}

\section{References}

1. O'Connell T, Rasanathan K, Chopra M. What does universal health coverage mean? Lancet. 2014;383(9913):277-9.

2. World Health Organization. Arguing for universal health coverage. Geneva: WHO; 2013.

3. World Health Organization. Health System Financing: The Path Towards Universal Health Coverage. Geneva: WHO; 2010.

4. Sustainable financing, universal health coverage and social insurance. World Health Assembly Resolution 58.33. 2005. http://www.who.int/health_financing/ documents/cov-wharesolution5833/en/. Accessed 16 February 2015.

5. Damrongplasit K, Melnick G. Funding, coverage, and access under Thailand's Universal Health Insurance Program: An update after ten years. Appl Health Econ Health Policy. 2015;13(2):157-66.

6. Marshall SJ. Developing countries face double burden of diseases. Bull World Health Organ. 2004;82(7):556

7. Borgonovi E, Compagni A. Sustaining universal health coverage: The interaction of social, political, and economic sustainability. Value Health. 2013;16:534-8.

8. Alebiosu C, Ayodele O. The global burden of chronic kidney disease and the way forward. Ethn Dis. 2005;15:418-23.

9. USRDS: Special Analyses. http://www.usrds.org/2014/view/img_v2_10.html Accessed 15 March 2016

10. White S, Chadban S, Jan S, Chapmanc J, Cass A. How can we achieve global equity in provision of renal replacement therapy? Bull World Health Organ. 2008;86:229-37.
11. Couser W, Remuzzi G, Mendis S, Tonelli M. The contribution of chronic kidney disease to the global burden of major noncommunicable diseases. Kidney Int. 2011;80(12):1258-70. doi:10.1038/ki.2011.368.

12. Liyanage T, Ninomiya T, Jha V, Neal B, Patrice HM, Okpechi I, et al. Worldwide access to treatment for end-stage kidney disease: a systematic review. Lancet. 2015:385(9981):1975-82. doi:10.1016/S0140-6736(14)61601-9.

13. Davies S. Peritoneal dialysis - current status and future challenges. Nat Rev Nephrol. 2013;9:399-408.

14. Taslim BB. Identifying the barriers to achieving sustainable dialysis programs in sub-Saharan Africa: Nigeria as a reference point. J Nephrol Ther. 2014;4: 186. doi:10.4172/2161-0959.1000186.

15. Yu AW, Chau KF, Ho YW, Li PK. Development of the "peritoneal dialysis first" model in Hong Kong. Peritoneal Dialysis International. 2007 Jun 1; 27(Supplement 2):S53-5.

16. Yang W, Hwang S. Taiwan Society of Nephrology. Incidence, prevalence and mortality trends of dialysis end-stage renal disease in Taiwan from 1990 to 2001: the impact of national health insurance. Nephrol Dial Transplant. 2008;23(12):3977-82. doi:10.1093/ndt/gfn406.

17. Lim T, Goh A, Lim Y, Zaher Z, Suleiman B. How public and private reforms dramatically improved access to dialysis therapy in Malaysia. Health Aff. 2010;29(12):2214-22. doi:10.1377/hlthaff.2009.0135.

18. Joint Learning Network. Thailand: Universal Coverage Scheme. Joint Learning Network. http://programs.jointlearningnetwork.org/content/ universal-coverage-scheme. Accessed 16 February 2015.

19. Rao A, Casula A, Castledine C. UK Renal Registry 17th Annual Report: Chapter 2 UK Renal Replacement Therapy Prevalence in 2013: National and Centre-specific Analyses. Nephron. 2015;129 Suppl 1:31-56.

20. Bresnahan M, Guan X, Smith S, Wang X, Edmundson J. Cultures of the soul: spiritual beliefs about organ donation in China and the United States. Chin J Commun. 2010;3(2):133-46.

21. Irving MJ, Tong A, Jan S, Cass A, Rose J, Chadban S, et al. Factors that influence the decision to be an organ donor: a systematic review of the qualitative literature. Nephrol Dial Transplant. 2012;27(6):2526-33. doi:10. 1093/ndt/gfr683.

22. Hebert P, Rivera J, Eng K, Lee R, Seto-Yee S. Improving organ donation in Chinese community in New York. In: Siegel JT, Alvaro EM, editors. Understanding organ donation: applied behavioral science perspectives. Chichester and Malden, MA: Wiley-Blackwell; 2010. p. xxii. 368.

23. Noppakun $K$, Ingsathit A, Pongskul C, Premasthian N, Avihingsanon $Y$, Lumpaopong A, et al. A 25-year experience of kidney transplantation in Thailand: Report from the Thai Transplant Registry. Nephrology. 2015;20(3):177-83.

24. Kanchanachitra C, Lindelow M, Johnston T, Hanvoravongchai $\mathrm{P}$, Lorenzo FM, Huong NL, et al. Human resources for health in southeast Asia: shortages, distributional challenges, and international trade in health services. Lancet 2011:377(9767):769-81.

25. Jensen $C E$, Sørensen P, Petersen KD. In Denmark kidney transplantation is more cost-effective than dialysis. Dan Med J. 2014;61(3):A4796.

26. Haller M, Gutjahr G, Kramar R, Harnoncourt F, Oberbauer R. Cost-effectiveness analysis of renal replacement therapy in Austria. Nephrol Dial Transplant. 2011; 26(9):2988-95

27. Jarl J, Gerdtham U-G. Economic evaluations of organ transplantations-a systematic literature review. Nordic J Health Econ. 2011;1(1):Jarl

28. Rocha MJ, Ferreira S, Martins LS, Almeida M, Dias L, Pedroso S, et al. Cost analysis of renal replacement therapy by transplant in a system of bundled payment of dialysis. Clin Transpl. 2012;26(4):529-31.

29. Klarenbach S, Manns B. Economic evaluation of dialysis therapies. Seminars in Nephrology. Philadelphia, PA: Elsevier; 2009.

30. Li P. Global burden of end-stage renal disease, solutions and future development. International Forum on Peritoneal Dialysis as a Priority Health Policy in Asia. Bangkok, November 27, 2014.

31. Leong G, Ngo L, Meng O, et al. National 21st report of the Malaysian Renal Dialysis Registry. 2013. http://203.115.198.108/Doc/PublicDoc_PB/ Publication/mdtr2013/FULL_REPORT_2013.pdf. Accessed 17 February 2015

32. Li $P$, Chow $K$. The cost barrier to peritoneal dialysis in the developing world-an Asian perspective. Perit Dial Int. 2001;21 Suppl 3:S307-13.

33. Registry TUR. UK Renal Registry 16th Annual Report. 2013. https://www. renalreg.org/reports/2013-the-sixteenth-annual-report/. Accessed 16 February 2015.

34. USRDS. Annual Data Report: Epidemiology of Kidney Disease in the United States. Bethesda, MD: National Institutes of Health, National Institute of Diabetes and Digestive and Kidney Diseases; 2014. 
35. Ho Y, Ka-Foon C, Choy B, et al. Hong Kong Renal Registry Report 2012. Hong Kong J Nephrol. 2013;15(1):28-43.

36. Praditpornsilpa K. Thailand Renal Replacement Therapy Registry Report. 2011. http://www.nephrothai.org/trt/trt.asp?type=TRT\&news_id=391. Accessed 22 January 2015.

37. Yu A, Chau K, Ho Y, Li P. Development of the "Peritoneal Dialysis First" Model in Hong Kong. Perit Dial Int. 2007;27(Supplement 2):S53-5.

38. Teerawattananon $Y$, Mugford $M$, Tangcharoensathien V. Economic evaluation of palliative management versus peritoneal dialysis and hemodialysis for endstage renal disease: evidence for coverage decisions in Thailand. Value Health. 2007;10(1):61-72

39. Suja A, Anju R, Anju V, Neethu J, Peeyush P, Saraswathy R. Economic evaluation of end stage renal disease patients undergoing hemodialysis. J Pharm Bioallied Sci. 2012;4(2):107-11. doi:10.4103/0975-7406.94810

40. Chuengsaman P. Psychosocial innovation for improved quality of life. International Forum on Peritoneal Dialysis as a Priority Health Policy in Asia; 27-28 November 2014; Courtyard Marriot Hotel. Bangkok. 2014.

41. Sinnakirouchenan R, Holley J. Peritoneal dialysis versus hemodialysis: risks, benefits, and access issues. Adv Chronic Kidney Dis. 2011;18(6):428-32.

42. Prodjosudjadi W, Suhardjono A. End-stage renal disease in Indonesia: treatment development. Ethn Dis. 2009:19(1 Suppl 1):S1-33-6.

43. Philhealth coverage for hemodialysis. July 6, 2015. http://www. healthphilippines.net/2014/08/philhealth-coverage-for-hemodialysis/. Accessed 22 January 2016.

44. Pa VJN. Hemodialysis in Asia. Kidney Dis. 2015;1:165-77. doi:10.1159/000441816.

45. Brown E. Peritoneal dialysis versus hemodialysis in the elderly. Perit Dial Int. 1999;19(4):311.

46. Hörl WH, de Alvaro F, Williams PF. Healthcare systems and end-stage renal disease (ESRD) therapies —an international review: access to ESRD treatments. Nephrol Dial Transplant. 1999;14 Suppl 6:10-5. doi:10.1093/ndt/ 14.suppl_6.10.

47. Goodlad C, Brown E. The role of peritoneal dialysis in modern renal replacement therapy. Postgrad Med J. 2013;89(1056):584-90. doi:10.1136/ postgradmedj-2012-131406

48. Li P, Chow K. Peritoneal dialysis-first policy made successful: perspectives and actions. Am J Kidney Dis. 2013;62:993-1005.

49. Chaudhary K, Harbaksh S, Ramesh K. Peritoneal dialysis first: rationale. Clin J Am Soc Nephrol. 2011;6(2):447-56.

50. Calman KC. The ethics of allocation of scarce health care resources: a view from the centre. J Med Ethics. 1994;20(2):71-4

51. Dukpa W, Teerawattananon Y, Rattanavipapong W, Srinonprasert V, Tongsri W, Kingkaew P, et al. Is diabetes and hypertension screening worthwhile in resource-limited settings? An economic evaluation based on a pilot of a Package of Essential Non-communicable disease interventions in Bhutan. Health Policy Plan. 2014;30(8):1032-43

52. Chootipongchaivat S, Luz A, Pilasant S, Tangsathitkulchai S, Tantivess S, Teerawattananon Y, et al. Technical Report: International Forum on Peritoneal Dialysis as a Priority Health Policy in Asia. Bangkok: Health Intervention and Technology Assessment Program (HITAP); 2014.

53. National Institute for Health and Care Excellence. Chronic kidney disease NICE quality standard 5. 2005. https://www.nice.org.uk/guidance/qs5. Accessed 2 February, 2015.

54. Bailey J. ACE inhibitors vs. ARBs for patients with diabetic kidney disease. Am Fam Physician. 2007;76(1):68-9.

55. Sittipreechachan P. Sharing experience of palliative care. J Nurs Sci. 2013; 30(3) 18-26.

56. The World Bank. Population, total. http://data.worldbank.org/indicator/SP. POP.TOTL. Accessed 16 February 2015.

57. The World Bank. GDP per capita (current US\$). http://data.worldbank.org/ indicator/NY.GDP.PCAP.CD. Accessed 16 February 2015.

58. The World Bank. Health expenditure, total (\% of GDP). http://data. worldbank.org/indicator/SH.XPD.TOTL.ZS. Accessed 16 February 2015.

59. International Diabetes Federation. IDF diabetes atlas sixth edition. 2014. http://www.diabetesatlas.org/across-the-globe.html. Accessed 3 February 2015

60. Bennett CL, Pei GK, Ultmann JE. Western impressions of the Hong Kong health care system. West J Med. 1996;165(1-2):37-42.

61. WHO and Department of Health, Hong Kong. Health Service Delivery Profile: Hong Kong (China). 2012. http://www.wpro.who.int/health_ services/service_delivery_profile_hong_kong_(china).pdf. Accessed 3 February 2015.
62. Food and Health Bureau. Health Expenditure: total expenditure on health (TEH) as \% of GDP. In: Health Statistics. http://www.fhb.gov.hk/statistics/en/ statistics/health_expenditure.htm. Accessed 17 February 2015.

63. Simmonds A, Hort K. Institutional analysis of Indonesia's proposed road map to universal health coverage. Melbourne: Nossal Institute for Global Health, University of Melbourne; 2013. Contract No: 33.

64. Widowati K. Indonesia aims for universal health coverage by 2019 International Health Policies. http://archief.internationalhealthpolicies.org/ archives/indonesia-aims-universal-health-coverage-2019/. Accessed 14 March 2016

65. Savedoff W, Smith A. Achieving universal health coverage: learning from Chile, Japan, Malaysia and Sweden. Maine: Results for Development Institute (R4D); 2011.

66. 2011-2016 National Objectives for Health, Health Sector Reform Agenda Monographs. DOH HSRA Monograph No. 12. Manila: Department of Health. 2016. www.doh.gov.ph/sites/default/files/publications/noh2016.pdf.

67. Paterno R. The Future of Universal Health Coverage: A Philippine Perspective Global Health Government. 2013. http://blogs.shu.edu/ghg/2013/09/18/thefuture-of-universal-health-coverage-a-philippine-perspective/. Accessed 3 February 2015

68. Kreng V, Yang $C$. The equality of resource allocation in health care under the National Health Insurance System in Taiwan. Health Policy. 2011;100(23):203-10. doi:10.1016/j.healthpol.2010.08.003.

69. International Monetary Fund. http://www.imf.org/external/pubs/ft/weo/ 2014/02/weodata/download.aspx. Accessed 14 March 2016.

70. Ministry of Health and Welfare, Taiwan. National Health Expenditure. 2013. http://www.imf.org/external/pubs/ft/weo/2014/02/weodata/download.aspx. Accessed 3 February 2015.

71. Tangcharoensathien V, Limwattananon S, Patcharanarumol W, Thammatacharee J. Monitoring and evaluating progress towards Universal Health Coverage in Thailand. PLoS Med. 2014;11(9):e1001726. doi:10.1371/ journal.pmed.1001726.

72. Majeed A. Universal health coverage in the United Kingdom. J Ambul Care Manage. 2003;26(4):373-7.

\section{Submit your next manuscript to BioMed Central and we will help you at every step:}

- We accept pre-submission inquiries

- Our selector tool helps you to find the most relevant journal

- We provide round the clock customer support

- Convenient online submission

- Thorough peer review

- Inclusion in PubMed and all major indexing services

- Maximum visibility for your research

Submit your manuscript at www.biomedcentral.com/submit 